\title{
Constructing Pedagogical Models for E-Learning
}

\author{
http://dx.doi.org/ijac.v4i3.1713 \\ PhD.Patricia Alejandra Behar \\ Federal University of Rio Grande do Sul, Porto Alegre, Rio Grande do Sul, Brazil
}

\begin{abstract}
This article brings forth an overview of the paradigmatic crisis and the introduction of new pedagogical practices. It also discusses the relationship between paradigm and pedagogical model, presenting a theoretical discussion on the concepts of pedagogical model for E-learning and its pedagogical architecture. To do so, the elements that are part of it such as organizational aspects, content, methodological and technological aspects are discussed. This theoretical discussion underlies the construction of a new pedagogical model for E-learning taking into account the grounds over which today's net society is based on: time and space. Examples of E-learning pedagogical models are presented.
\end{abstract}

Index Terms-pedagogical model, E-learning, paradigmatic change, pedagogical practices

\section{INTRODUCTION}

During the last decade Brazilian educational institutions have been marked by a significant process of change, in particular with the introduction of E-learning in the educational process. It is said that this is the moment of transformation where the present paradigms of society are not enough to account for relations, needs and social challenges. The idea of a society that is centered on work is being replaced by an idea of a society which values education, within a new totality, called in many contexts Information Society, or Net Society. Such change means that an Industrial Society emphasizing a teaching culture gives way to a Net Society which emphasizes a learning culture, calling for the construction of a new educational model. It is necessary, therefore, to investigate which elements have been transformed and keep on changing and which have come anew into the scene.

The educational model in use in the Industrial Society privileges the technical teaching as its purpose is to train individuals for the performance of roles, according to their aptitudes. In this model, the pedagogical practice is far from the daily lives of students and generates little curiosity emphasizing the piling of knowledge, values and norms of society. As a result, students tend to lose interest because they cannot see the purpose of what is being taught [7].

In the Net Society, learning is characterized by an appropriation of knowledge in a concrete reality. That is, the starting point is the real situation experienced by the learner who is supported by the mediating and coordinating presence of a professor, committed to his/her students and to the construction of knowledge, who, in turn, aims to respond to the principles of significant learning. This process takes for granted that relevant information is offered to the learner so that he/she can relate it with concepts already present or in pre-existence in his/her cogni- tive structure and that end up influencing learning and the meaning attributed to new concepts built.

In this perspective, knowledge is conceived as a result of the subject's actions upon reality, the student taking the position of a protagonist in the learning process which is built cooperatively, in a renewed and reflexive communicative relation with the other subjects. In this paradigm, the pedagogical practice considers the process and the actions more meaningful than the resulting products.

In this context E-learning can help solve some of the problems of Brazilian education. Through the use of technological tools that enable distant learning, government, public and private institutions hope to tackle the giant educational deficit in the country and find the way of digital inclusion in the Information Society.

Thus, E-learning [8] can be defined as an organized set of learning which is characterized, basically, by the physical separation between teacher and learners and the existence of some kind of mediating technology that allows for the interaction among them, in this case, the virtual learning environments. In spite of the fact that it can be organized based on different pedagogical models, it is important to highlight that E-learning is education, that is, it is not just a technological system or a means of communication.

Therefore, this learning system offers instruments that can transform Brazilian education, supported by information and communication technologies (ICT). It is believed that, without the intensive use of technology, Brazilian institutions will not manage to reach all their range of formation/capacitation in education. However, this demands studies about theoretical and methodological proposals and call for widespread accounts of experiences as well as reflections upon them and their possibilities.

There is great expectation about E-learning, especially at College level, as we can see in programs created by the Ministry of Education (MEC) SEED (Secretaria especial de educação a distância, in Portuguese) that is coordinating actions throughout the country to enable the insertion of technological renovations in the teaching and learning processes as a strategy to democratize and increase the quality standard of Brazilian Education. These actions and programs aim to promote the development and incorporation of TICs and the development of E-learning techniques applied to conventional didactics and pedagogy. Besides, the SEED encourages research and development of programs and projects addressed to the construction of new concepts and practices in Brazilian public institutions.

As it is, the present study aims to describe basic concepts for the definition of a Pedagogical Model (MP) addressed to E-learning. It is understood that this Pedagogical Model will be based on the construction of new paradigms that respond to the emerging needs of a new teacher/student profile. This way, the consolidation of new models, with solid epistemological, pedagogical, organi- 
zational, technological and methodological pillar structures can be subsidized. We are, therefore, speaking of a possible paradigmatic change.

\section{A PARADIGMATIC CRISIS AND NEW PEDAGOGICAL PRACTICES}

It is possible to say that there is, nowadays, an educational paradigmatic crisis concerning the advent of information and communication technology and, particularly, concerning virtual learning environments. These paradigmatic changes are due to a need to innovate considering that there are new subject profiles about to enter the work market, subjects who need to be prepared to think in different ways, to make use of new tools, less linear ones and more hypermediatic or hypertextual ones, focusing on a new way of learning, with greater emphasis not on product any longer but on process.

It is therefore necessary to face the crisis and come to terms with it allowing for a new look to replace conservative pedagogical practices in search of a transition. It is hard to lose old intellectual habits, overcome resistance, old classroom methods and the old paradigms but it is necessary to update, to be unbalanced, to re-adapt to the new, to the unknown, to what generates insecurity. The availability of new concepts, proposing new methodologies, theories, new standards to define reality, school, call for a new view of the world, a world of challenges, uncertainty, the search for something better.

To educate, in general terms, is to advance in successive leaps, it is to fit in, to fit the mold. To visualize the new, its structure and evolution have become a determining factor of progress and, when we look at education from a closer point of view, it is possible to say that pedagogical practices in use so far have been suffering from a secular paralysis, "formatted" in space and time. Pedagogical practices remain in an epistemological conservativeness and the traditional paradigms keep on ruling the perception of reality in schools.

It is evident, not only due to the introduction of Information and Communication Technologies, that a paradigmatic crisis is hitting Education. But also, it is through it that the need to undertake meaningful changes in educational practices and, consequently, in the pedagogical model has become more obvious. Thus, a new pedagogical space is being generated and its characteristics are: the development of competences and abilities, respect to individual's pace, the building of learning communities and networking [1]. It is necessary to focus on capacitation, learning, open and E-learning and knowledge management. Studies about the construction of knowledge, autonomy, authorship and interaction contribute to the construction of a heterarchic space, where cooperation, mutual respect, solidarity and activities centered on the learner and on the identification and solution of problems. It is in this process that the new emerging model is being engendered.

\section{Relating Paradigm to Pedagogical Model}

To understand the concept of model it is necessary to go through the term paradigm, which is of common use and calls for a previous analysis of its meaning in the educational context. Thomas Kuhn, in his book The Structure of Scientific Revolutions [3] re-interpreted the concept of paradigm and defined it as a theoretical framework, built upon a set of methodological rules and axioms, established within a given scientific community for a period of time. Thus, it is possible to say that it is a system of reference upon which theories are tested, evaluated and if necessary, revised. As such, a paradigm is a set of theories or a dominant explication system in any particular scientific area for a period of time. But why for just a period of time? Kuhn states that there are shifts in scientific evolution and he refers to them as "paradigm changes."

According to Kuhn's definition, paradigm is the representation of a standard model that is followed. It is a philosophical matrix premise, in other words, it is the knowledge that engenders studies in a scientific field; a scientific realization with methods and values conceived as model, an initial reference that is the support of a model. We know that Kuhn's paradigm concept includes methods, statements, values and the scientific community. In this study we're not inlcuding the discussion about the community.

Therefore, when a change of paradigm is concerned, it concerns a new way of seeing, feeling, living within a new reference. Scientific research aims to promote changes in ways the world is understood. Breaks with the past take place, often enabling new ways of understanding the world and this is followed by theory reconstruction and by experiment re-interpretation. Other changes involve only little innovation and virtually leave intact the great structure of knowledge of areas.

Paradigm changes are felt in all areas of knowledge and many of them take place from inside out. In the case of Education, a paradigmatic change occurred from outside in due to the introduction of information and communication technologies, driving institutions to a new profile and to a reformulation of roles among "actors" involved. Among them, education managers, teachers, professors, students and monitors.

The term paradigmatic change has lately been addressed to information and communication technologies (ICT) and, particularly, to E-learning which is one of the key factors for the shifts in the educational area. The world has new axes in the concepts of time and space. In this sense, a new paradigm is emerging. This new paradigm is built upon a new set of references through the confluence of a body of theories, ideas that explain and orient a new way of living, educating and learning.

Upon reporting such trends to the educational area, it is essential to elucidate the paradigms that support changes in pedagogical practice. It is important to highlight that educational paradigms constitute a reference system that explains a determined educational phenomenon. Thus, there is more and more need to build theoretical axes taking into account the "new" trends, contemplating aspects of epistemological, methodological and ontological nature.

Scientific activity tries to understand, explain and predict world phenomena [4]. Science tries to simplify and generalize reality through laws, principles and models. The concept of model emerges, therefore, as an attempt to establish a relation to reality by analogy. The model is a figurative system that reproduces reality in a more abstract form, almost schematically and is used as reference [2].

So, models emerge in the core of paradigms. We can say that each model has its own expression within each paradigm and is differentiated by the objectives it aims to 
achieve, by the environment and by expected results which, naturally, lead into differentiating the strategies used. As our focus here is education, this model is denominated Pedagogical Model and it is rooted in learning theories.

In this study, the expression "Pedagogical Models" represents a teaching/learning relation, supported by learning theories whose bases are in different epistemological fields. All this points to a determined paradigm.

Any built model is named after a theory (piagetian, rogerian, vygostskian, skinnerian, etc.) or after a paradigm (interactionist, humanist, instructionist, etc.). However, this terminology may not correspond to the supporting epistemology, contradicting the theories mentioned [2]. It is understood, therefore, that a pedagogical model can be based on one or more learning theories.

Picture 1 presents the process of construction of a pedagogical model. In it, we go from a dominant paradigm which, in general, influences the present learning theories as well as other scientific theories. From this point of view, subjects build their own personal model that is shared with peers.

Upon bringing the discussion to E-learning, the situation becomes more complex as we try to establish a new meaning for the word model. In this perspective, the concept of model is strongly linked to information and communication technologies.

Numerous didactic pedagogical propositions for Elearning have been made lately. As new technologies are developed, they are incorporated into the educational system and E-learning issues are seen more from the technological point of view than from the pedagogical one. This brings on negative results causing school failure because the focus is on technological changes and not paradigmatic ones.

Therefore, the goal is to define premises for a Pedagogical Model for E-learning that can respond to the paradigm changes as stated by Kuhn [4]. We are speaking of a new dominium in education, going from a ratio of one-to-many and/or many-to-many, with defined space-time concepts and where oral communication predominates to an interaction of one-to-many, one-to-one and also many-tomany. This new dominium is based on multimedia communication, and co-presence in space and time is dispensed. It is a new ground where the mere adaptation of pedagogical models derived from presential education cannot be made.

It is here that a paradigmatic rupture means the construction of new axes that will sustain the management of a new way of knowing, of living, of being, and of doing, distance wise.

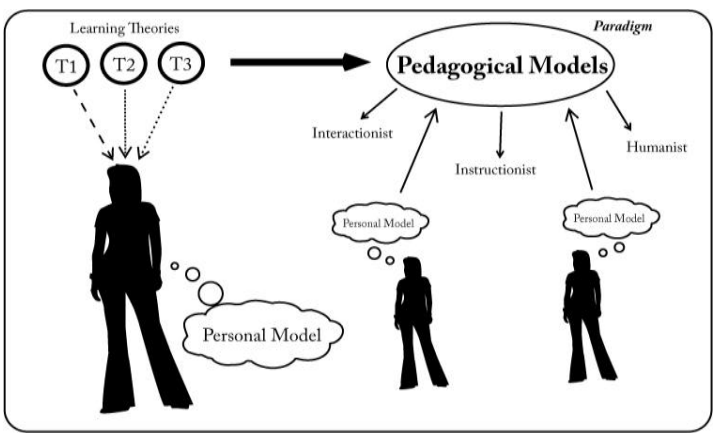

Figure 1. Construction of Pedagogical Models

\section{OPERATIONALIZING THE CONCEPT OF PEDAGOGICAL MODEL FOR E-LEARNING}

Within the framework presented, the concept of pedagogical model for E-learning is understood as a system of theoretical premises that represent, explain and guide the way the curriculum is approached and that is consolidated in the pedagogical practices and in the interactions professor-student-object of study/knowledge.

The pedagogical model entails a multidimensional approach of all the participating variables and its elements, as we are going to discuss now. From the afore mentioned concept, we highlight the fact that the elements of a pedagogical model for E-learning have a structure supported by a determined paradigm and matched to one or more educational theories that are used as a learning orienting matrix. This structure is shown in Picture 2 where, at its core, the element denominated Pedagogical Architecture (PA) can be seen.

The PA consists of (1) grounds for the planning/pedagogical proposition (organizational aspects): goals of distant teaching/learning process, space and time organization and expectations in relation to the performance of participants, also called class social organization; (2) content - instructional material and/or computer resources used - learning objects, software and other learning tools; (3) activities, ways of interaction/communication, evaluation procedures and the organization of all these elements in a didactic sequence for learning (methodological aspects); (4) definition of virtual learning environment and its functionalities, communication tools such as video and/or teleconference, among others (technological aspects).

Organizational aspects are concerned with: definition of learning goals in terms of an "intention list"; class social organization where groupings and separations are established, roles are defined, rights and duties of each "actor" (be it teacher, student or tutor); time and space systematization considering flexibility issues that virtual learning make possible. According to Zabala [12] space and time variables are, in general, not explicit in pedagogical models but they have fundamental importance in any space of pedagogical intervention. In presential education these two variables "seem" unchangeable in school organization because time is systematized in fixed periods and space in classrooms. However, in E-learning they have dimensions yet to be explored by teachers who have strong concepts of presential education in their educational practice.

In relation to content, it can be any kind of material and/or element used in order to build knowledge. Accord-

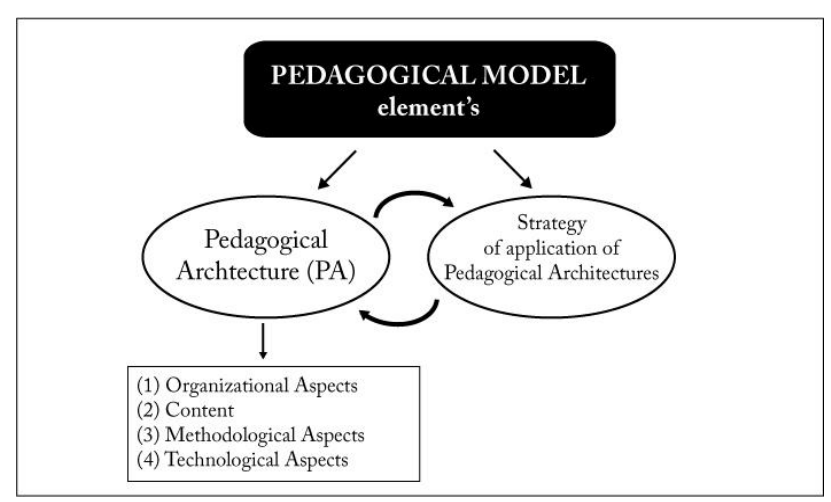

Figure 2. Elements of a pedagogical model for E-learning 
ing to Zabala [12], the contents one intends to work with can be classified following a conceptual, factual, attitudinal and procedural approach. This group of elements must be carefully planned so that knowledge, capacities, skills and competencies are built and developed.

In sum, the content is "what" is going to be covered. Thus, it can be very simple instructional material, an educational software, Web pages or learning objects. Contents can integrate several media such as sound, image, video, text and/or hypertext, contemplating different learning styles [5]. Besides, the methodology of work ("how") can be inserted into this type of material. In this case, the methodological aspects are integrated to this element of architecture.

Methodological aspects concern not only a selection of techniques, procedures and computer resources to be used in class but also the relation and structuring that this combination of elements will have. This will depend on the objectives to be achieved and on the emphasis given to content that is previously established. Methodological aspects have a direct relation with the objectives of the course as well as with evaluation issues. The act of evaluating concerns the collection, the analysis and the data synthesis that is configurated as an evaluation object. Therefore, it is important to have in mind: what is being evaluated? How? Why? By whom? What do we want to evaluate? Will evaluation be continuous? Formative? Additive? Which tools from the virtual environment can help evaluation? Will evaluation be presential, semi or totally distant? These instruments should supply data to show whether objectives were achieved (or not) according to their description in the pedagogical planning.

Within the technological aspects, the Virtual Learning Environment (AVA) and its functionalities and/or resources of communication and interaction that are to be used must be defined and the choice should be based on those that best adapt to the course/program in question.

Nowadays, there are numerous Virtual Learning Environments that support teaching-learning processes based on the Web, either originating from the academic or commercial areas. Each of them has, implicitly or explicitly, conceptions about how the process occurs and aims to target specific objectives. Therefore, what we need to consider is the model of the virtual learning environment: centered on the user or on the course and, once this is clear, select which best fits the characteristics of the course.

In what way, then, do pedagogical architectural applications differ from one another? It is necessary to take into account the social, emotional and personal aspects of the "actors" involved in E-learning, which means that another important aspect to be highlighted and reflected upon as a "differential" in the process of teaching/learning (there are variations from teacher to teacher), is the strategies of application of the pedagogical architecture. These constitute the dynamics of the pedagogical model.

The strategy of application of Pedagogical Architectures is defined as a didactic act that addresses the articulation and adjustment of any architecture to a situation of learning of a certain group (group, course, class). Thus, it is possible to say that the application strategy refers to the way the teacher will put his personal model in practice (as shown in picture 1)
It is understood, therefore, that the strategies for the application of pedagogical architecture are responsible for their dynamism, in other words, the dynamism of the constitutive process of the pedagogical model. The pedagogical architecture may, therefore, through its strategies of action, contemplate the social, emotional and personal aspects that are part of the teaching-learning process in virtual environments.

Examples of construction of Pedagogical Models for ELearning are presented as follows.

\section{EXAMPLES OF CONSTRUCTION PEDAGOGICAL MODEL FOR E-LEARNING}

\section{A. Pedagogical Model for the discipline Virtual Learning Workshops}

The pedagogical model built for the discipline "Virtual Learning Workshops" originated in an interactionist perspective, where the elaboration and planning process took into account the target public as well as the understanding about the teaching level over which the methodological strategies were laid upon in such discipline.

Theme axes were then established, their organization in terms of space and time for the performance of activities, synchronous and asynchronous moments, reading timetables, discussions and postings of production and individual and/or group activities. This organization previewed the timetable after thoroughly examining the contents worked with and the descriptions of the procedures adopted.

The activities to be carried out by students were also made explicit through the discipline page and through the material used. The contents worked with (in the form of learning objects available at http://www.nuted. ufrgs.br/?page id=79) were: 1) Collective Work Support Technology; 2) COMVIA - VIRtual Learning COMmunities; 3) Construction of Learning Objects; 4) Construction of Virtual Workshops.

The general mapping of the discipline (conceptual map or storyboard), in picture 3 , illustrates all the activities and planned strategies. It consists of documental production encompassing thoroughly all the contents and procedures belonging to the produced material in each theme previewed in the discipline. The organizational structure of the pedagogical model cares for the alignment and group participation as a whole, where students and teachers weave their actions together.

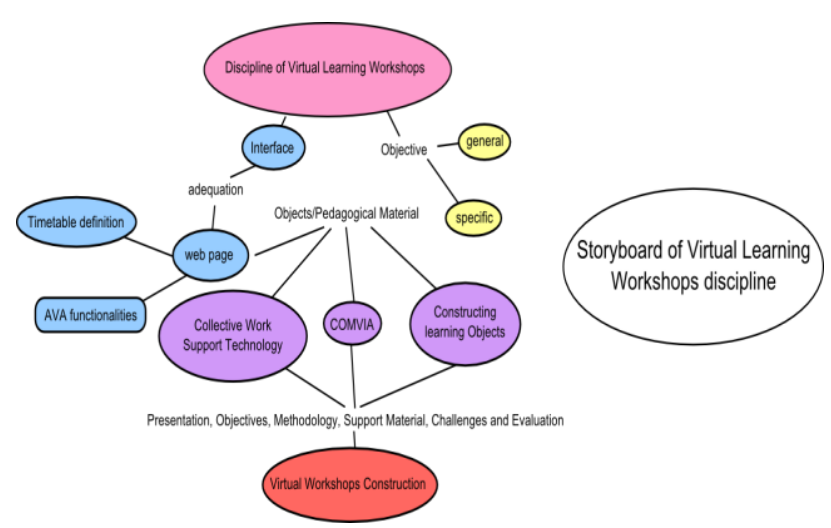

Figure 3. Concept Map of Virtual Learning Workshops discipline 
The work on the discipline relied on the use of the virtual learning environment ROODA (Cooperative Learning Network - is one of the platforms of distant education used by UFRGS; available in: http://www.ead. ufgs.br/rooda) to support the development of activities and synchronous and asynchronous communication and interaction among students/teachers. Through the discipline's web page and through the links available in the environment, access to materials of each content was possible as well as general guidelines and readings suggested throughout the term. One of the strategies used to keep track of students' learning was their participation/records in the functionalities of ROODA. Among them, contributions were made to the Forum, Diary Board, Chat, individual and group Webfolio. The evaluation followed in a formative and continuous perspective. There were four meetings, three of them presential and one virtual, a total of 20 hours.

From the page of the discipline (http://www.nuted. ufrgs.br/oficinas_2007) it was possible to access curricula organization (with program, objectives, content authors learning objects), calendar, materials, timetable of presential and virtual meetings, discussion dates, and the realization of synchronous virtual activities, theoretical support and evaluation criteria.

To follow, two of the objects used in the discipline are shown, as illustration and exemplification, and the way they were used and integrated into ROODA. As it has been mentioned above, the content for the discipline were elaborated as Learning Objects. One of them was COMVIA, that deals with Virtual Learning Communities and other Collective Work Support Technology and illustrated in picture 4 .

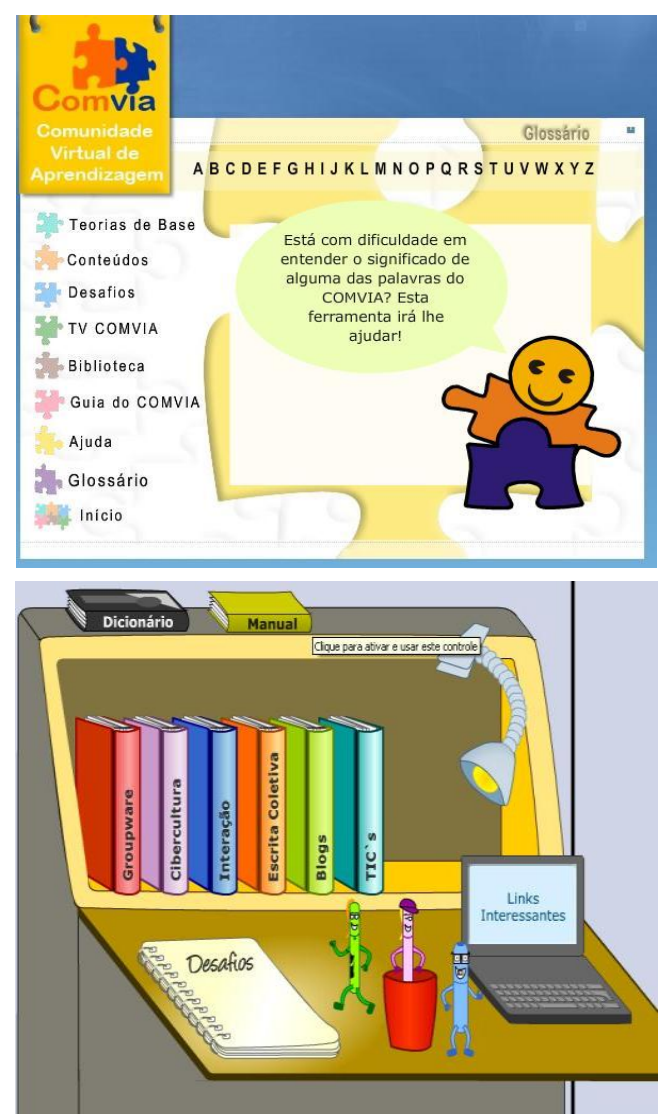

Figure 4. Interface of two leaning Objects: Virtual Learning Communities and Collective Work Support Technology
Classes were permeated by incentives to interindividual exchanges among students, fostering confrontation of different viewpoints. In presential moments, collective writing potential was discussed, particularly when supported by digital resources and their pedagogical implications. Students exposed their perspectives about the issue, discussed particularities, possible gains and possible limitations that may be found throughout the process. They met virtually through Chat, Forum, Groups and A2 of ROODA [2], where contents were discussed and proposed challenges developed. The productions constructed collectively were posted in Group Webfolio which allowed research sharing among participants. Moreover, each participant was able to access the body of the work editing it successively.

Thus, it is possible to say that integrating AVA ROODA (picture 5) to the 4 discipline objects: COMVIA, Collective Work Support Technology (in this paper just two were shown but methodology with the others was the same), Learning Objects Construction and Construction of Virtual Workshops seemed to be extremely important because it allowed not only the construction per se of individual/collective production but also the offer of support to synchronous and asynchronous exchanges among students. Such resources enabled interaction and collectivity promoting moments of collaboration and cooperation.

Evaluation of the Pedagogical Model developed in this discipline pointed to a high rate of benefit on the part of students once their productions seemed to qualify to be applied in real educational contexts, therefore responding to the objectives proposed in its pedagogical planning.

Experience exchange and interaction among students were encouraged during the discussions about the themes being worked on, through the ROODA environment. We understand that, through experienced interactions, it is possible to tread different paths toward the construction of new knowledge. During the presential classes, aspects regarding the conception, creation and pedagogical implications of virtual learning communities in different educational contexts were discussed. Students could share their impressions, reflections and doubts, acknowledging the potential of virtual learning communities as resources supporting Distant Education. In the virtual meeting, students met online, using the ROODA environment, in order to solve the challenges assigned them.

The challenges were solved in groups. The students needed to meet virtually or presentially out of class time. This necessity made it possible for these students to con-

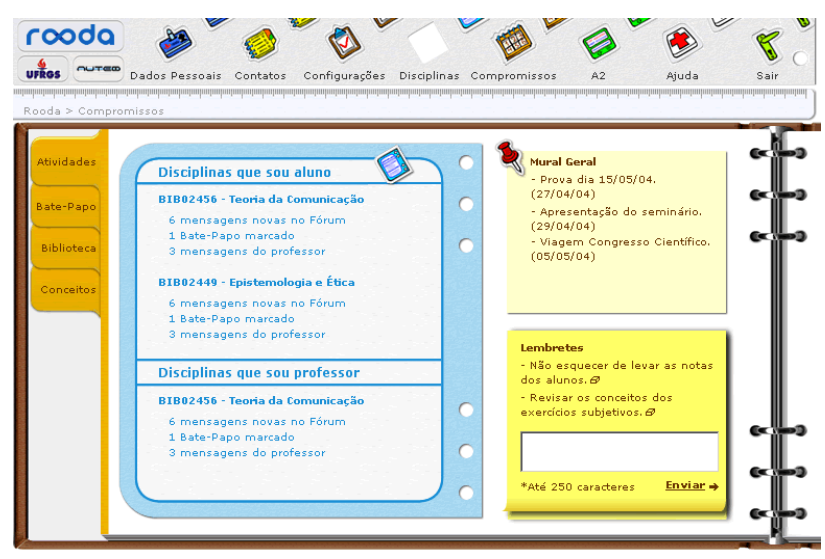

Figure 5. Initial screen of ROODA environment 
stitute a virtual space with their groups, through the ROODA environment that resulted in the constitution of collective spaces among participants. It was possible to observe, thus, the formation of virtual learning communities within the group to carry out the challenges that were proposed. In order to do so, the students used, basically, ROODA tools, as we described above.

\section{B. Pedagogical model using IPTV}

In this part of the article, we are going to discuss an experience - different from the previous ones - developed in an E-Learning specialization course, brought forth by Centro Interdisciplinar de Novas Tecnologias na Educação da UFRGS (CINTED) and the Universidade Virtual do Maranhão (UNIVIMA).

The innovative aspect of this course is centered on assisting people with heterogeneous backgrounds regarding their knowledge of information technology in education, their culture, their professional realities, among other differences. The course was addressed to eleven settings in different towns in the state of Maranhão.

The construction of the Pedagogical Model for the course had to consider, besides the issues related to the public and their experiences, the technological resources available.

A differential that can be pointed out in relation to other experiences presented is the fact that the pedagogical planning of the course had to be based on a different technical structure. The virtual synchronous classes were taught live through videoconference via satellite and watched by students in their settings through equipment such as projectors and television sets, and followed by teachers-tutors through IPTV software. For the presentation of the course proposal and the development of activities of each discipline in the E-Learning modality, the virtual learning environment TelEduc was used and a site that enabled the access to the information about the course and to videos produced and edited with the recording of the classes.

On Picture 6, the screen of the interface IPTV software used during moments of videoconference of the course described. Afterwards, synchronous moments transmitted simultaneously to the 11 settings in the state of Maranhão, and all the asynchronous communication and postings of planned activities took place through TelEduc.

The coordination of the course was in charge of managing the administrative aspects of the course and of guiding the teacher coordinators of each discipline. These were in charge of elaborating the material, the activities and of methodological guidance. This information was passed on to the teacher-tutors of each setting who, in their turn, had to apply the tasks, mediate and evaluate activities in each discipline.

We highlight in this course the experience of the discipline "Information and Communication Technologies Applied to Education". In this discipline, the weekly meetings were virtually made through videoconference. Among the themes, the following were worked with: (1) Introduction to the discipline and construction of webpage through Composer software; (2) Use of Composer software: research about personal experience, current situation of information technology in Education, among others; (3) Use of Learning Object ITC - discussion in the forum; (4) Composer (evaluation of digital resource, software,

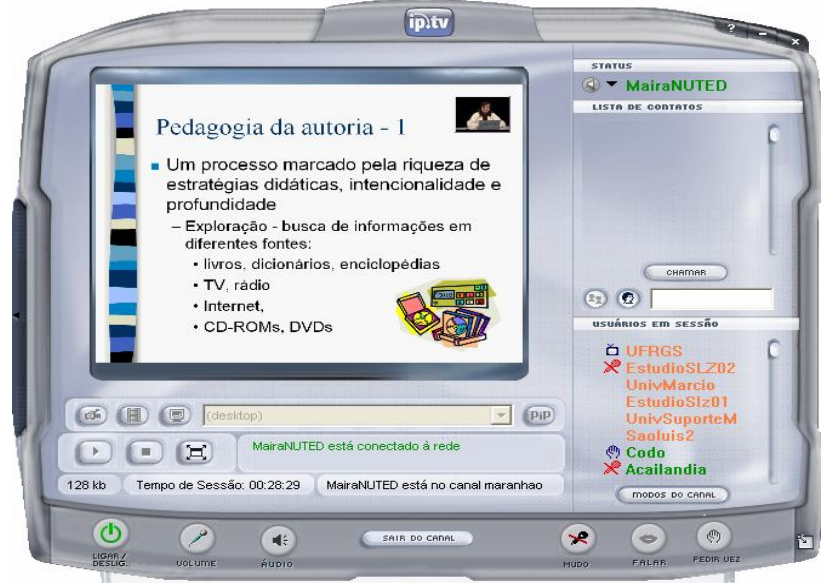

Figure 6. Interface of IPTV Software

site,..); (5) CSCW/CSCL/Interaction/interactivity; (6) Cooperative Learning (text production in the functionality GROUPS of TelEduc); (7) Conceptual Maps - concept web - use of software CMap Tools; (8) Use of Learning Object Visit at School - observation of the use of information technology in schools; (9) Closing of activities publication of observation report; and (10) presential test.

The contents used in the discipline were in the form of Web pages and had been applied in other courses as well as the learning objects. It is important to mention, however, that the course modality (extension course), the methodology adopted, the ways of interaction/communication, the virtual learning environment (TelEduc) and its functionalities, are the differential and defined the configuration of the pedagogical model of the course. Another aspect that can be pointed out about the pedagogical model of a course known as 'UNIVIMA' highlights the importance of making digital libraries available, tips for research in printed material, videos, presentations, support links and extra material to expand investigation about themes worked with in each discipline. Thus, we realize that the Pedagogical Model can aggregate different digital tool that can support moments of research as well as moments of communication and production so as to supply the demands of a more heterogeneous public.

Based on the theoretical premises presented in this study, we have described so far some very different experiences of application of pedagogical models that allowed for adjustment of organizational, technological, methodological aspects and contents according to different educational needs.

It is to be highlighted, therefore, that a Pedagogical Model may be based on a certain epistemological concept but its real application will depend on the pedagogical action that will guide material development and its methodological strategy. Hence, even a Pedagogical Model developed according to an interactionist perspective where discussion, collective construction, challenge are deemed important, may gain a completely new meaning if based on an epistemological perspective supported by an instructionist paradigm.

\section{CONCLUSIONS}

In the present study, a framework for the concept of pedagogical model was exposed, conceived as shared representations of a relationship system established in the 


\section{Constructing PEDAgogicAl Models OR E-LEARNING}

pedagogical activity. Its constituting elements were analyzed highlighting the construction of a pedagogical architecture and of the variables that constitute it, focusing on E-learning.

The objective was to present the elements of a "possible" pedagogical model, supported by organizational, epistemological, technological and methodological parameters, from a different viewpoint.

We aim to contribute to the consolidation of new pedagogical practices to be implemented through E-learning. Thus, these paradigmatic changes may serve to make the new actors more and more in charge of their own histories, converging, diverging and/or simply crossing paths in the process.

We can say that the network of knowledge in Elearning is being constituted, engendering several knots, but also finding several directions that open up and configurate new ways. Among them, the pedagogical models for E-learning which still demand research, investigation and growth.

\section{REFERENCES}

[1] Behar, Patricia Alejandra; Meirelles, Silvia (2006). The Virtual Learning Environment ROODA: An Institutional Project of Long Distance Education. Journal of science education and technology, EUA, v. 15, n. 2, p. 159-167.

[2] Behar, P. A et al. (2009). Modelos Pedagógicos em Educação a Distância. Porto Alegre: Artmed.

[3] Berger, P. \& Luckmann, T.(1966). "The Social Construction of Reality". Garden City: Double- day.
[4] Kuhn, Thomas S. (1996). The Structure of Scientific Revolutions (3rd edition). Chicago: the University of Chicago Press.

[5] Paloff, Rena M. e PRATT, Keith. (2004). O Aluno Virtual: um guia para trabalhar com estudantes on-line. Porto Alegre: Artmed.

[6] Piaget, Jean. (1973). Estudos Sociológicos. Rio de Janeiro: Forense.

[7] Mason, Robin; Rennie, Frank. (2008) E-learning and Social Networking Handbook - Resourses for Higher Education. NY: Routledge.

[8] Moore, M.; Kearsley. (2008). Educação a Distância: uma visão integrada. São Paulo: Cengage Learning.

[9] Tomasello, M. (2003). Origens Culturais da Aquisição do Conhecimento Humano. São Paulo: Marins Fontes. (Tópicos Collection).

[10] Vermeersch (org.).(2006). Iniciação ao Ensino a Distância, Gruntvig: Brussel.

[11] Wertsch, J. (1999). "La Mente en Acción”. Buenos Aires: Aique.

[12] Zabala, Antoni (1998). "A prática educativa: como ensinar". Porto Alegre: ArtMed.

\section{AUTHOR}

BEHAR, Patricia A. Education College, Federal University of Rio Grande do Sul. Digital Technology Nucleous in Education (NUTED). Avenida Paulo Gama 110, Porto Alegre. Brasil (http://www.nuted.ufrgs.br; email: pbehar@terra.com.br)

This article is an extended version of a presentation at ICELW 2011 The International Conference on E-learning in the Workplace, held from June 8th-10th, 2011 at Columbia University, New York, NY, USA. Received June 21st, 2011. Published as resubmitted by the author August 5th, 2011. 